\title{
Improved Regression Analysis of Temperature- Dependent Strain-Gage Balance Calibration Data
}

\author{
N. Ulbrich ${ }^{\dagger}$ \\ Jacobs Technology Inc., Moffett Field, California 94035
}

\begin{abstract}
An improved approach is discussed that may be used to directly include first and second order temperature effects in the load prediction algorithm of a wind tunnel strain-gage balance. The improved approach was designed for the Iterative Method that fits strain-gage outputs as a function of calibration loads and uses a load iteration scheme during the wind tunnel test to predict loads from measured gage outputs. The improved approach assumes that the strain-gage balance is at a constant uniform temperature when it is calibrated and used. First, the method introduces a new independent variable for the regression analysis of the balance calibration data. The new variable is defined as the difference between the uniform temperature of the balance and a global reference temperature. This reference temperature should be the primary calibration temperature of the balance so that, if needed, a tare load iteration can be performed. Then, two temperature-dependent terms are included in the regression models of the gage outputs. They are the temperature difference itself and the square of the temperature difference. Simulated temperature-dependent data obtained from Triumph Aerospace's 2013 calibration of NASA's ARC-30K five-component semi-span balance is used to illustrate the application of the improved approach.
\end{abstract}

\section{Nomenclature}

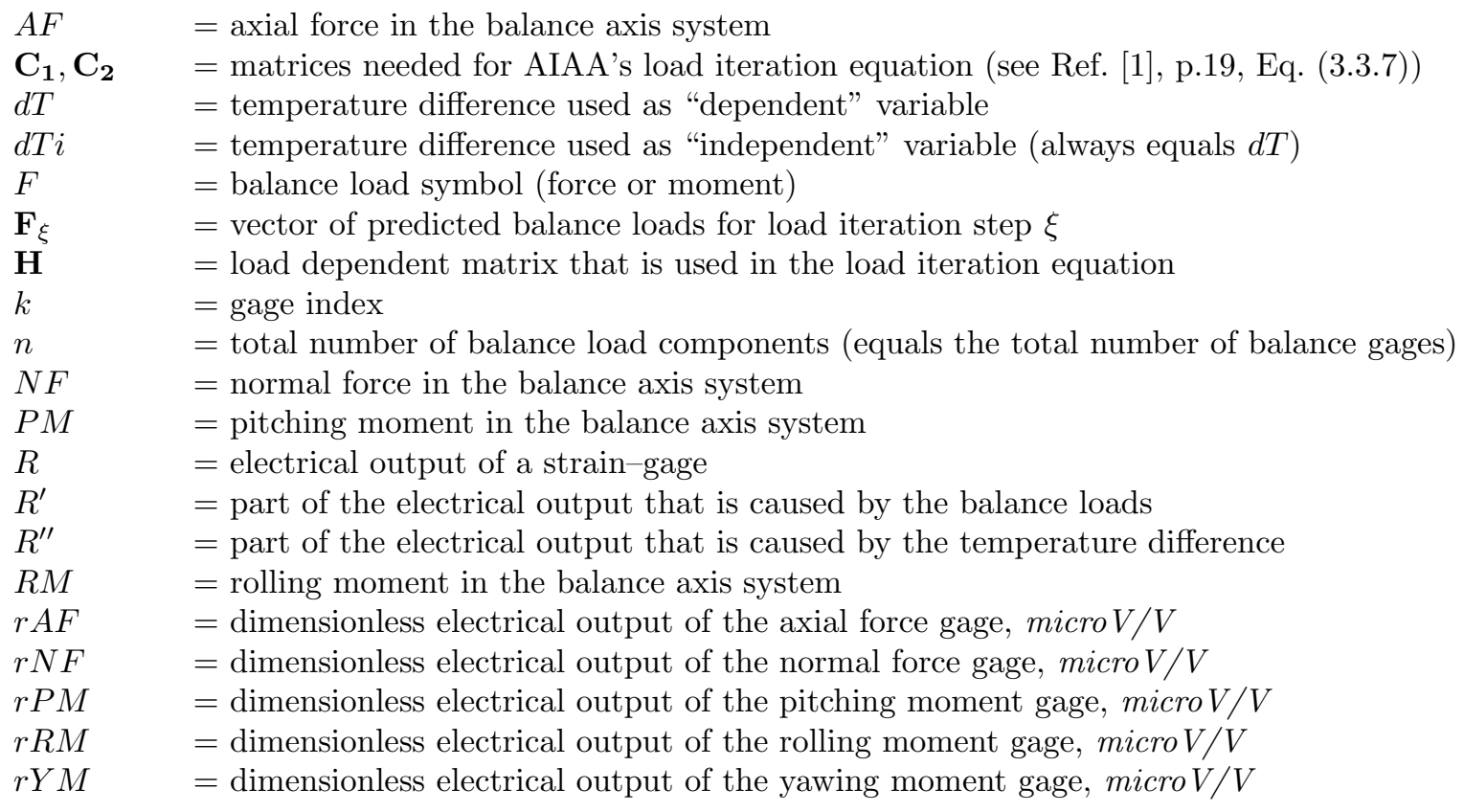

\footnotetext{
$\dagger$ Aerodynamicist, Jacobs Technology Inc.
} 


\begin{tabular}{|c|c|}
\hline$T$ & $=$ measured uniform temperature of the balance \\
\hline$T_{\circ}$ & $=$ global reference temperature of the balance \\
\hline$Y M$ & $=$ yawing moment in the balance axis system \\
\hline$c_{0}, c_{1}, \ldots$ & $=$ regression coefficients of the fitted strain-gage outputs \\
\hline$\Delta \mathbf{R}$ & $=$ vector of gage outputs and temperature difference that is an input for the load calculation \\
\hline$\mu$ & $=$ total number of coefficients that are exclusively associated with balance loads \\
\hline$\xi$ & $=$ load iteration step index \\
\hline
\end{tabular}

\section{Introduction}

Different techniques are used in the aerospace testing community to predict strain-gage balance loads from gage outputs during a wind tunnel test. The load prediction is usually based on the result of a multivariate regression analysis of strain-gage balance calibration data. The Iterative Method, for example, first fits strain-gage outputs of a balance as a function of loads that were applied during the calibration. Then, resulting regression coefficients are converted to data reduction matrix coefficients so that loads can be predicted from measured gage outputs during a wind tunnel test using a load iteration scheme (see Refs. [1] to [4] for detailed discussions of the Iterative Method).

By design, the Iterative Method makes the assumption that the number of "independent" variables, i.e., balance loads, equals the number of "dependent" variables, i.e., strain-gage outputs. This implicit requirement made it difficult in the past to include a separate term in the regression model of a straingage output that describes temperature effects. Therefore, some researchers completely avoided the use of temperature-dependent regressors in the equations of the Iterative Method by simply assuming that the regression coefficients associated with the balance loads are a function of temperature. This approach has two disadvantages: (i) it requires a separate least squares fit for each calibration temperature of the balance, and, (ii) additional post-calibration data processing is needed to characterize the temperature-dependency of the regression coefficients of the balance loads for use during the wind tunnel test.

In 2011, the present author developed an alternative to the data processing approach that is described in the previous paragraph. He showed that it is possible to use "temperature-dependent" regressors sideby-side with "load-dependent" regressors in math models of gage outputs as long as the temperature is used as both an "independent" and "dependent" variable in the equations that the Iterative Method applies (for more detail see Refs. [5], [6]). The author already described in a previous paper how temperature sensitivities of strain-gage outputs could potentially be combined with the Iterative Method so that temperature dependencies are included to a certain degree in the prediction of balance loads (see Ref. [6]). In 2014 he developed a refinement of his original approach that uses a more general description of temperature effects for the regression analysis of strain-gage balance calibration data. Basic ideas of the refined approach will be discussed in the next section of the paper. Afterwards, simulated temperature-dependent calibration data of a five-component semi-span balance is used to illustrate the application of the new approach.

\section{Extended Regression Model of the Gage Outputs}

In principle, the author's improved approach for the inclusion of temperature effects in regression models of the gage outputs applies the Principle of Superposition. It is simply assumed that temperature effects cause an "offset" in the electrical outputs that is a function of the difference between the uniform balance temperature and a global reference temperature. This temperature difference becomes the new "independent" variable in the regression models of the gage outputs. It has to be used as both an "independent" and "dependent" variable in the equations of the Iterative Method so that the load iteration scheme defined in Ref. [1] can still be applied (see also the detailed discussion of this topic in Ref. [5]). The temperature difference can be expressed as follows

$$
d T=T-T_{\circ}
$$

where $T$ is the uniform balance temperature and $T_{0}$ is the chosen global reference temperature. This reference temperature should be the primary calibration temperature of the balance so that, if needed, a tare load iteration can be performed to estimate loads caused by the calibration hardware and the metric part of the 
balance (see, e.g., Ref. [1], p. 17 and pp. 25-40, for a discussion of the tare load iteration process). Ideally, the reference temperature should be located within the range of all uniform temperatures that the balance is expected to experience during the wind tunnel test.

Now, after assuming that (i) temperature effects influencing the gage outputs can be described by both a linear and a quadratic term and that (ii) no justification for the use of a temperature-dependent cross-product term exists, the following two new regressors are introduced in the regression model of each strain-gage output:

$$
\text { one new independent variable }: d T \quad \Longrightarrow \quad \text { two new regressors : } d T,(d T)^{2}
$$

Then, assuming that the balance has a total number of $n$ gages and a total number of $n$ load components, the "expanded" regression model of a gage output with index $k$ becomes:

$$
R(k)=R^{\prime}(k)+R^{\prime \prime}(k) \quad ; \quad 1 \leq k \leq n
$$

where

$$
\begin{gathered}
R^{\prime}(k)=c_{0}(k)+c_{1}(k) \cdot F(1)+c_{2}(k) \cdot F(2)+\cdots+c_{\mu}(k) \cdot\left|F^{3}(n)\right| \\
R^{\prime \prime}(k)=c_{\mu+1}(k) \cdot d T+c_{\mu+2}(k) \cdot(d T)^{2}
\end{gathered}
$$

The symbol $R(k)$ in Eq. $(2 a)$ above describes the total electrical output of the chosen gage output. $R^{\prime}(k)$ is the part of the total output that is associated with balance loads (see load symbols $F(1), \ldots, F(n)$ ). It is identical with the regression model of the gage outputs that AIAA recommends as an upper bound for use with the Iterative Method (see, e.g., Ref. [1], Eq. (3.1.2) or Eq. (3.1.3)). $R^{\prime \prime}(k)$ is the part of the total output that is associated with the temperature difference (see symbol $d T$ ). The symbols $c_{0}(k), c_{1}(k), \ldots, c_{\mu+2}(k)$ are the final regression coefficients of the total electrical output of the gage. For clarity, Eq. (2a) can be expressed in slightly different form. We can write for $1 \leq k \leq n$ :

$$
R(k)=\underbrace{c_{0}(k)+c_{1}(k) \cdot F(1)+\cdots+c_{\mu}(k) \cdot\left|F^{3}(n)\right|}_{\text {terms associated with calibration loads }}+\underbrace{c_{\mu+1}(k) \cdot d T+c_{\mu+2}(k) \cdot(d T)^{2}}_{\text {terms associated with temperature }}
$$

In addition, the regression model of the new "dependent" variable $d T$ can be expressed as follows:

$$
\underbrace{d T}_{\text {dep. }}=0+0 \cdot F(1)+0 \cdot F(2)+\cdots+0 \cdot\left|F^{3}(n)\right|+1.0 \cdot \underbrace{d T}_{\text {indep. }}+0 \cdot(d T)^{2}
$$

Equations $(3 a)$ and $(3 b)$ describe the set of $n+1$ linear equations that define the least squares problem of the temperature-dependent balance calibration data set. Fortunately, the regression coefficients of the "dependent" variable $d T$ defined in Eq. (3b) are implicitly known as $d T$ is used as both a "dependent" and "independent" variable. Consequently, coefficient $c_{\mu+1}(n+1)$ is " 1 " and $c_{\rho}(n+1)$ is " 0 " for $\rho \neq \mu+1$. At this point, the extended set of "independent" variables, "dependent" variables, and regression coefficients defined in Eq. (3a) can be summarized as follows:

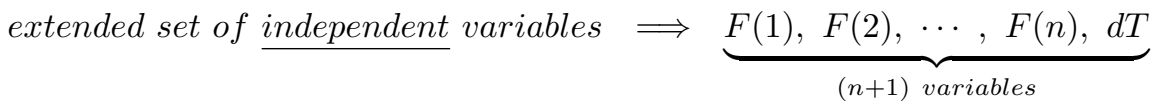

$$
\begin{aligned}
& \text { extended set of dependent variables } \Longrightarrow \underbrace{R(1), R(2), \cdots, R(n), d T}_{(n+1) \text { variables }} \\
& \text { extended set of regression coefficients } \Longrightarrow \underbrace{c_{0}(k), c_{1}(k), \cdots, c_{\mu+2}(k)}_{1 \leq k \leq n}
\end{aligned}
$$

The extended variable and coefficient sets above can be used to construct a least squares fit that defines a data reduction matrix for the temperature-dependent balance calibration data set. This matrix supplies the coefficients for the load iteration equation that the Iterative Method uses for the prediction of balance 
loads (see again Ref. [5] for more details). The load iteration equation has the following general format (from Ref. [1], p. 19, Eq. (3.3.7)):

$$
\mathbf{F}_{\xi}=\underbrace{\left[\mathbf{C}_{1}^{-1}\right]}_{\text {matrix }} \cdot \Delta \mathbf{R}-\underbrace{\left[\mathbf{C}_{1}^{-1} \mathbf{C}_{2}\right]}_{\text {matrix }} \cdot \mathbf{H}\left(\mathbf{F}_{\xi-1}\right)
$$

where vector $\mathbf{F}$ of the "independent" variable set is defined as

$$
\mathbf{F}_{(n+1) \times 1}=\left[\begin{array}{c}
F(1) \\
F(2) \\
\vdots \\
F(n) \\
d T
\end{array}\right]
$$

and vector $\boldsymbol{\Delta} \mathbf{R}$ of the "dependent" variable set is defined as

$$
\Delta \mathbf{R}_{(n+1) \times 1}=\left[\begin{array}{c}
R(1)-c_{0}(1) \\
R(2)-c_{0}(2) \\
\vdots \\
R(n)-c_{0}(n) \\
d T
\end{array}\right]
$$

and matrices $\mathbf{C}_{\mathbf{1}}^{-1}$ and $\mathbf{C}_{\mathbf{1}}^{-1} \mathbf{C}_{\mathbf{2}}$ have the coefficients of the data reduction matrix that results from the fit of the balance calibration data. The symbol $\mathbf{H}\left(\mathbf{F}_{\xi-1}\right)$ represents a rectangular matrix that only depends on load estimates of the previous iteration step (see Ref. [1], p. 18, for a detailed definition of the matrix).

A simulation of a temperature-dependent calibration data set of a five-component semi-span balance is used in the next section of the paper to illustrate the improved approach to include temperature effects in the prediction of loads of a strain-gage balance.

\section{Discussion of Example}

Recent calibration data of NASA's ARC-30K five-component semi-span balance was selected to illustrate the improved approach to include temperature effects in the load prediction equations used by the Iterative Method. The ARC-30K balance was calibrated at Triumph Aerospace (Force Measurement Systems) in 2013 and commissioned for use in the wind tunnel in the fall of 2014 (see Ref. [7] for additional details associated with the calibration of the ARC-30K). Figures 1a and $1 \mathrm{~b}$ show the balance during manufacturing and after installation in the test section floor of the Ames 11ft Transonic Wind Tunnel. Table 1 below summarizes important features of the balance and the calibration data set that was used for the present study.

Table 1: Balance and calibration data set characteristics of the ARC-30K balance.

\begin{tabular}{|c|c|}
\hline CHARACTERISTIC & DESCRIPTION \\
\hline \hline BALANCE TYPE & 5 -component semi-span balance \\
\hline DIMENSIONS & diameter $=15.0$ inches $($ metric flange $) ;$ height $=18$ inches \\
\hline CALIBRATION DATE AND PLACE & June $/$ July 2013 at Triumph Aerospace \\
\hline CALIBRATION HARDWARE & Triumph Aerospace's Large Load Rig (LLR) \\
\hline NUMBER OF ORIGINAL DATA POINTS & 70 degF \\
\hline CALIBRATION TEMPERATURE & 7459 \\
\hline
\end{tabular}


The ARC-30K balance was sized so that it is suitable for semi-span model testing of a commercial transport aircraft in the Ames 11ft Transonic Wind Tunnel. Table 2 below lists load capacities of the balance:

Table 2: Load capacities of the ARC-30K balance.

\begin{tabular}{|c|c|c|c|c|c|}
\hline & NF, lbs & PM, in-lbs & YM, in-lbs & RM, in-lbs & AF, lbs \\
\hline CAPACITY & 30,000 & 300,000 & 150,000 & $1,300,000$ & 3000 \\
\hline
\end{tabular}

The balance was originally calibrated using Triumph's Large Load Rig (LLR). The LLR is capable of loading the balance to capacity. In addition, the LLR can also apply complex load combinations that a semi-span model is expected to experience during a wind tunnel test.

During the calibration of the ARC-30K a total of 1459 data points were recorded at a single constant temperature of approximately $70 \mathrm{deg} F$. In other words - no data was collected that could be used to model temperature effects on the gage outputs. Therefore, an assumed temperature dependency of the gage outputs had to be simulated using the original calibration data so that elements of the improved approach of including temperature effects in regression models of gage outputs could be tested. Table 3 below summarizes hypothetical relationships that were chosen to model the temperature-dependency of the five balance gages.

Table 3: Assumed temperature-dependency of the ARC-30K's gage outputs.

\begin{tabular}{|c|c|}
\hline GAGE OUTPUT & ASSUMED TEMPERATURE DEPENDENCY $\left(T_{\circ}=70 \operatorname{deg} F\right)$ \\
\hline$r N F$, microV $/ V$ & $r N F(T)=r N F\left(T_{\circ}\right)+1.0 \cdot\left(T-T_{\circ}\right)+0.010 \cdot\left(T-T_{\circ}\right)^{2}$ \\
$r P M$, microV $/ V$ & $r P M(T)=r P M\left(T_{\circ}\right)+1.1 \cdot\left(T-T_{\circ}\right)+0.009 \cdot\left(T-T_{\circ}\right)^{2}$ \\
$r Y M$, microV $/ V$ & $r Y M(T)=r Y M\left(T_{\circ}\right)+0.9 \cdot\left(T-T_{\circ}\right)+0.012 \cdot\left(T-T_{\circ}\right)^{2}$ \\
$r R M$, microV $/ V$ & $r R M(T)=r R M\left(T_{\circ}\right)+0.8 \cdot\left(T-T_{\circ}\right)+0.009 \cdot\left(T-T_{\circ}\right)^{2}$ \\
$r A F$, microV $/ V$ & $r A F(T)=r A F\left(T_{\circ}\right)+0.7 \cdot\left(T-T_{\circ}\right)+0.009 \cdot\left(T-T_{\circ}\right)^{2}$ \\
\hline
\end{tabular}

The symbols $r N F, r P M, r Y M, r R M$ and $r A F$ represent the electrical outputs of the five balance gages. The symbol $T$ identifies the assumed uniform temperature of the balance. The symbol $T_{\circ}$ represents the original calibration temperature of $70 \operatorname{deg} F$. It is also used as the global reference temperature for the data analysis.

In theory, any temperature set different from the reference temperature of $70 \operatorname{deg} F$ could be used to illustrate the new approach of including temperature-dependent data in the Iterative Method. For simplicity, it was decided to simulate gage outputs at $50 \operatorname{deg} F$ and $90 \operatorname{deg} F$ by using the original calibration data at $70 \operatorname{deg} F$ as a baseline. The resulting total calibration data set, i.e., the set consisting of original plus simulated data, would be capable of supporting both first and second order temperature-dependent terms in the regression models of the gage outputs. Therefore, the total calibration data set consisted of 4377 data points, i.e., 1459 original data points plus 2918 simulated data points. Figure 2 shows parts of the contents of a calibration data input file that has both the original and simulated calibration data.

An analysis of the 4377-point calibration data set was performed using NASA's BALFIT regression analysis tool (see Refs. [8] and [9] for details about BALFIT). The Iterative Method was chosen for both regression analysis and load prediction. The corresponding extended set of "dependent" variables, "independent" variables, and regression coefficients can be summarized as follows:

$$
\begin{aligned}
& \text { extended set of six dependent variables } \Longrightarrow r N F, r P M, r R M, r Y M, r A F, d T \\
& \text { extended set of six independent variables } \Longrightarrow N F, P M, R M, Y M, A F, d T i
\end{aligned}
$$

where

$$
d T=d T i=T-T_{\circ} ; T_{\circ}=70 \operatorname{deg} F
$$


The ARC-30K is a highly linear single-piece balance design. Therefore, no absolute value terms of the load components were included in the regression models of the five gage outputs. BALFIT's regression model search process was applied to the data in order to prevent "over-fitting" of the gage outputs. The resulting "optimized" regression models of the five gage outputs are depicted in column format in Fig. 3 (individual regression model terms are identified at the beginning of each row; all chosen regression model terms are marked using black rectangles).

It can clearly be seen in Fig. 3 that the temperature difference is being used as both a "dependent" and "independent" variable as the regression model of the "dependent" variable $d T$ only uses the single term $d T i$ (the symbol $d T i$ indicates the use of $d T$ as an "independent" variable). In addition, BALFIT's automated regression model term selection process correctly deduced from the temperature-dependent calibration data that both $d T i$ and $(d T i)^{2}$ are "significant" for all five gages. This result is expected as the assumed temperature dependencies defined in Table 3 are "hidden" in the simulated gage outputs of the calibration data.

Figure 4 lists all regression coefficients that were computed as a result of the least squares fit of the simulated calibration data. The fitted coefficients of terms $d T i$ and $(d T i)^{2}$ are marked using red boxes. Table 4 below compares "fitted" coefficients of the terms $d T i$ and $(d T i)^{2}$ with corresponding "exact" values.

Table 4: Comparison of the regression coefficients of $d T i$ and $(d T i)^{2}$.

\begin{tabular}{|c|c|c|c|c|c|c|}
\hline TERM & FITTED/EXACT & $r N F$ & $r P M$ & $r Y M$ & $r R M$ & $r A F$ \\
\hline$d T i$ & exact (from Table 3) & 1.00000 & 1.10000 & 0.90000 & 0.80000 & 0.70000 \\
& fitted (from Fig. 4) & 1.00000 & 1.10000 & 0.90000 & 0.80000 & 0.70000 \\
\hline$(d T i)^{2}$ & exact (from Table 3) & 0.01000 & 0.00900 & 0.01200 & 0.00900 & 0.00900 \\
& fitted (from Fig. 4) & 0.00999 & 0.00879 & 0.01205 & 0.00903 & 0.00894 \\
\hline
\end{tabular}

The comparison of the fitted and exact coefficient values of the term $d T i$ is perfect. In addition, the comparison of the fitted and exact coefficient values of the term $(d T i)^{2}$ is very good. These results indicate that the improved approach of modeling temperature effects on gage outputs of a balance with a uniform temperature distribution is working as intended. The reader has to keep in mind that the simulated data set was obtained from "real-world" calibration data of the balance. Consequently, larger differences between "fitted" and "exact" values of the coefficients of $(d T i)^{2}$ can be explained by the fact that the regression models of the gage outputs have picked up data imperfections that are, by design, contained in the simulated data.

Figure 5 shows the final data reduction matrix of the temperature-dependent calibration data. This matrix can be used in combination with the load iteration scheme of the Iterative Method (Eq. (4)), the gage outputs, and the temperature difference for the prediction of the balance loads in the wind tunnel.

Figure 6 shows the final load residuals of the total calibration data set that consists of 4377 original and simulated data points. Overall, the performance of the balance is very good considering the fact that the balance calibration data set consisted of a large number of complex combined loadings.

\section{Summary and Conclusions}

An improved approach was presented in the paper that may be used to include temperature effects in regression models of strain-gage outputs of a wind tunnel balance. The improved approach introduces the difference between the measured uniform balance temperature and a global reference temperature as a new independent variable for the calibration of the balance. Two new regressors are defined that are exclusively a function of this temperature difference. They are included in an extended regression model of the gage outputs that the Iterative Method needs for the prediction of balance loads from measured gage outputs during a wind tunnel test. Simulated temperature-dependent calibration data obtained from Triumph Aerospace's 2013 calibration of the ARC-30K five-component semi-span balance was successfully used to illustrate key elements of the improved approach.

The improved approach has one key advantage when compared with alternate load prediction approaches that use the Iterative Method. It allows for the direct application of the Iterative Method by simply introducing 
the temperature difference as both an "independent" and "dependent" variable during both calibration data analysis and balance load prediction. Consequently, no "customized" processing equations have to be implemented in the data system of a wind tunnel as a temperature-dependent data reduction matrix can simply be treated like the matrix of a balance that has one additional independent/dependent variable.

\section{Acknowledgements}

The author would like to thank Tom Volden of Jacobs Technology for his critical and constructive review of the final manuscript. The work reported in this paper was supported by the Wind Tunnel Division at NASA Ames Research Center under contract NNA09DB39C.

\section{References}

${ }^{1}$ AIAA/GTTC Internal Balance Technology Working Group, Recommended Practice - Calibration and Use of Internal Strain-Gage Balances with Application to Wind Tunnel Testing, AIAA R-091-2003, American Institute of Aeronautics and Astronautics, Reston, Virginia, 2003.

${ }^{2}$ Ulbrich, N., and Volden, T., "Strain-Gage Balance Calibration Analysis Using Automatically Selected Math Models," AIAA 2005-4084, paper presented at the 41st AIAA/ASME/SAE/ASEE Joint Propulsion Conference, Tucson, Arizona, July 2005.

${ }^{3}$ Ulbrich, N., and Volden, T., "Application Of A New Calibration Analysis Process to the MK-III-C Balance," AIAA 2006-0517, paper presented at the 44th AIAA Aerospace Sciences Meeting, Reno, Nevada, January 2006.

${ }^{4}$ Ulbrich, N., "Comparison of Iterative and Non-Iterative Strain-Gage Balance Load Calculation Methods," AIAA 2010-4202, paper presented at the 27th AIAA Aerodynamic Measurement Technology and Ground Testing Conference, Chicago, Illinois, June/July 2010.

${ }^{5}$ Ulbrich, N., "Iterative Strain-Gage Balance Calibration Data Analysis for Extended Independent Variable Sets," AIAA 2011-0949, paper presented at the 49th AIAA Aerospace Sciences Meeting, Orlando, Florida, January 2011.

${ }^{6}$ Ulbrich, N., "Application of Temperature Sensitivities during Iterative Strain-Gage Balance Calibration Analysis," AIAA 2011-5597, paper presented at the 47th AIAA/ASME/SAE/ASME Joint Propulsion Conference, San Diego, California, July/August 2011.

${ }^{7}$ Lynn, K. C., Commo, S. A., Ulbrich, N., Harris, C., "Experimental Design Considerations for Calibration of Semi-Span Force Measurement Systems," AIAA 2014-0276, paper presented at the 52nd AIAA Aerospace Sciences Meeting, National Harbor, Maryland, January 2014.

${ }^{8}$ Ulbrich, N., and Volden, T., "Development of a User Interface for a Regression Analysis Software Tool," AIAA 2010-0932, paper presented at the 48th AIAA Aerospace Sciences Meeting, Orlando, Florida, January 2010.

${ }^{9}$ Ulbrich, N., and Volden, T., BALFIT - Software Tool for the Regression Analysis of Multivariate Data, User Guide (3rd edition), Jacobs Technology Inc., prepared for NASA Ames Research Center under contract NNA09DB39C, October 2014. 


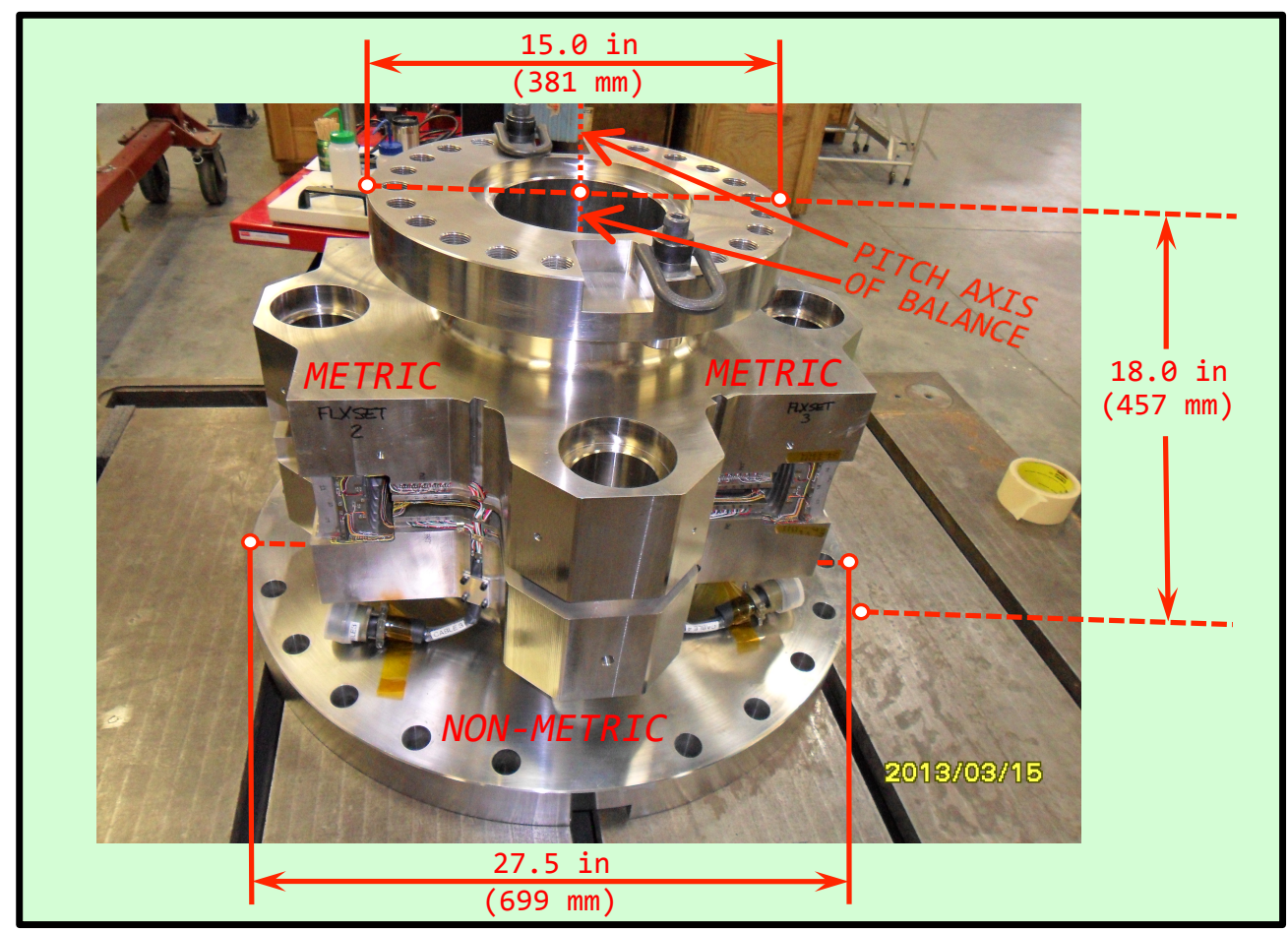

Fig. 1a NASA's ARC-30K 5-component semi-span balance.

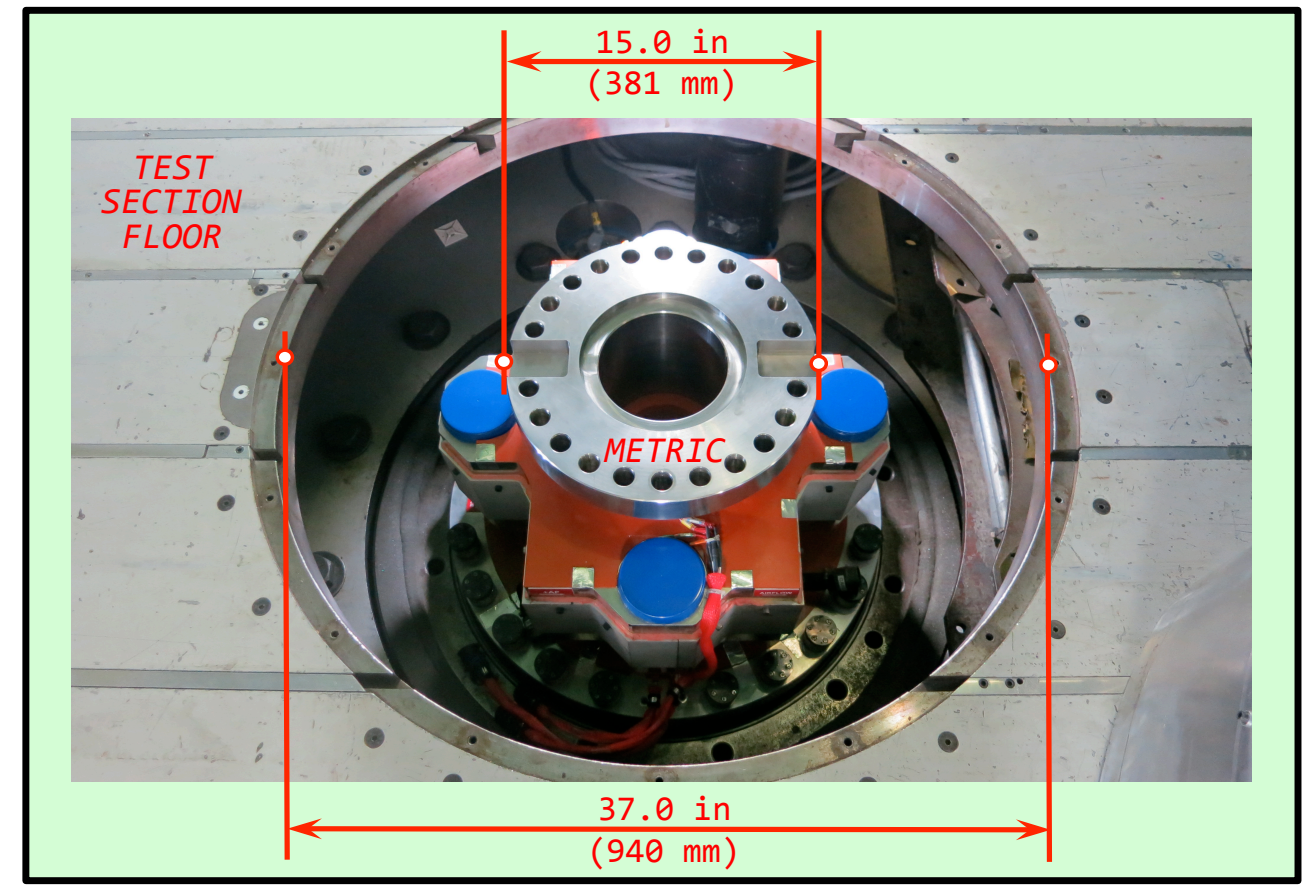

Fig. 1b Installation of the ARC-30K balance in the floor of the Ames 11ft Transonic Wind Tunnel. 


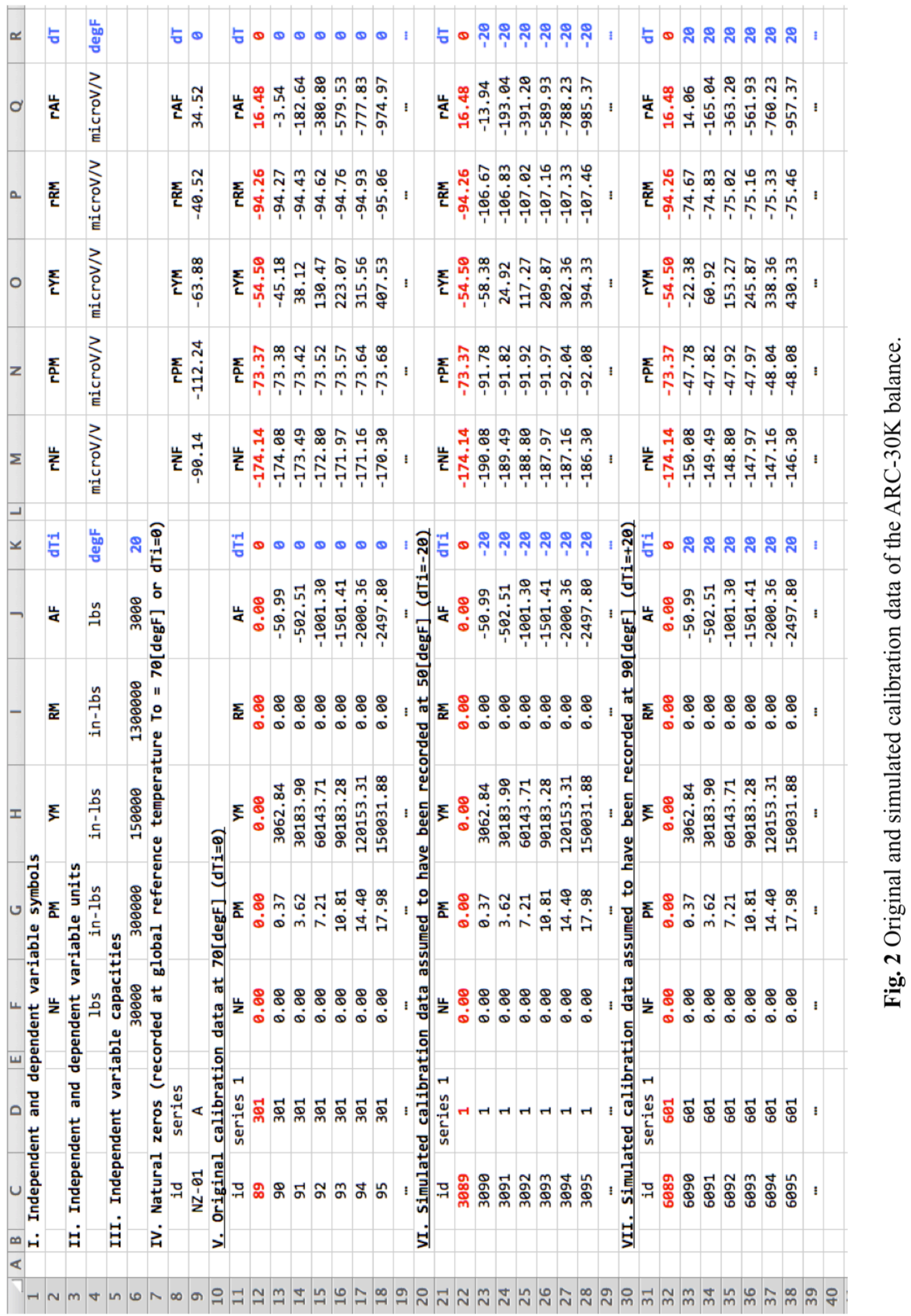



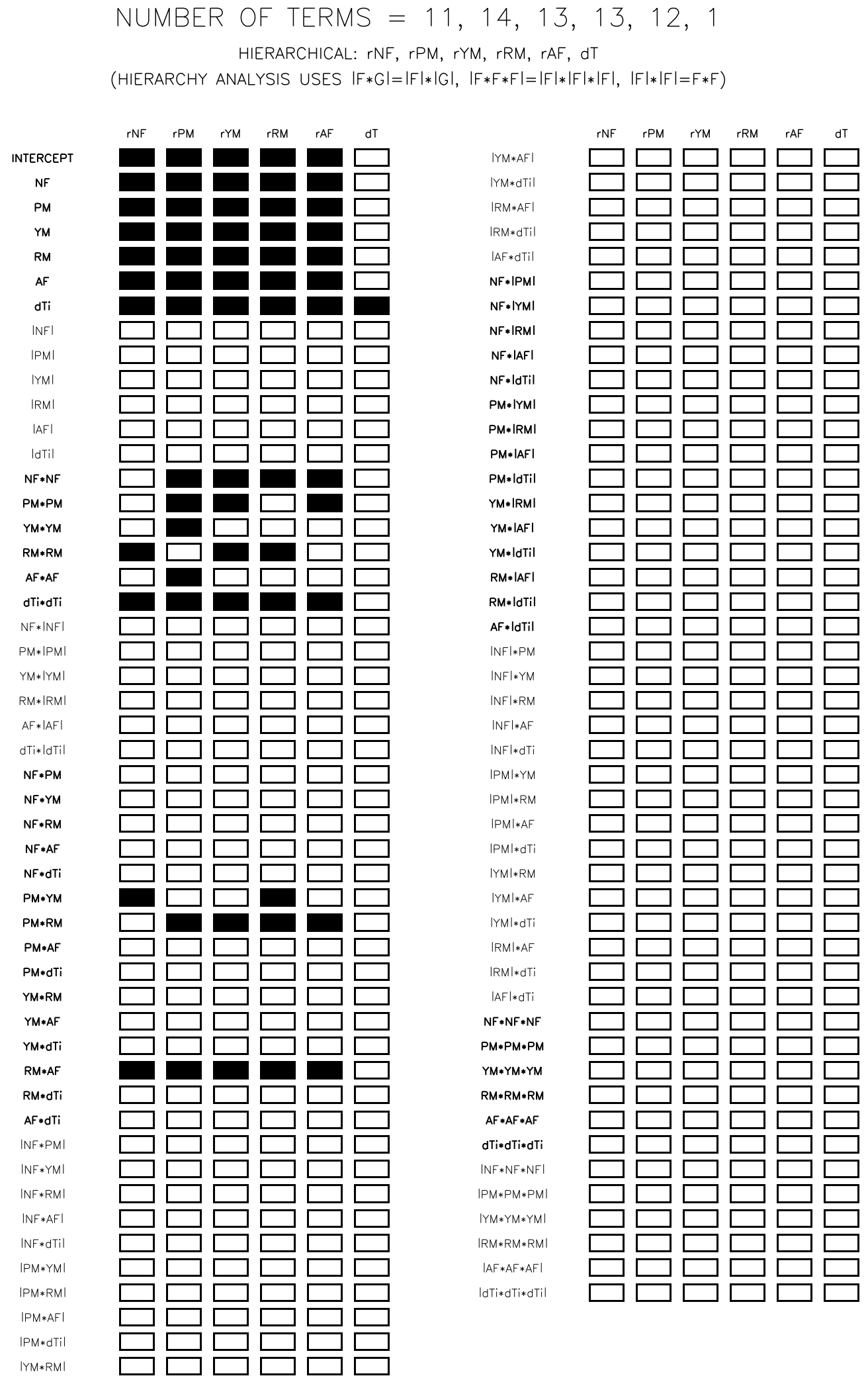

Fig. 3 Optimized regression models of the gage outputs of the ARC-30K balance. 


\begin{tabular}{|c|c|c|c|c|c|c|c|}
\hline INDEX & TERM & $\mathrm{rNF}$ & rPM & rYM & rRM & rAF & dT \\
\hline 1 & INTERCEPT & $-9.012208 e+01$ & $-1.123363 e+02$ & $-6.386578 e+01$ & $-4.050774 e+01$ & $+3.452281 e+01$ & 0 \\
\hline 2 & $\mathrm{NF}$ & $+4.040841 e-02$ & $+8.873827 e-05$ & $+8.466777 e-05$ & $-1.923540 e-03$ & $-3.674487 e-04$ & 0 \\
\hline 3 & PM & $-1.062855 e-04$ & $+5.551059 e-03$ & $+3.998764 e-06$ & $+6.922002 e-06$ & $-2.459394 e-05$ & 0 \\
\hline 4 & YM & $-5.327869 e-06$ & $+2.860829 e-06$ & $+3.069503 e-03$ & $-1.524219 e-06$ & $-1.219140 e-05$ & 0 \\
\hline 5 & $\mathrm{RM}$ & $+2.372123 e-05$ & $-4.395771 e-06$ & $+3.671878 \mathrm{e}-06$ & $+1.058854 \mathrm{e}-03$ & $-2.666958 e-06$ & 0 \\
\hline 6 & AF & $-1.864776 e-03$ & $+3.432262 e-04$ & $-8.136127 e-04$ & $+1.992452 e-04$ & $+3.963488 e-01$ & 0 \\
\hline 7 & $\mathrm{dTi}$ & $+1.000000 e+00$ & $+1.100000 e+00$ & $+9.000000 e-01$ & $+8.000000 e-01$ & $+7.000000 e-01$ & $+1.000000 e+00$ \\
\hline 8 & $|N F|$ & 0 & 0 & 0 & 0 & 0 & 0 \\
\hline 9 & |PMI & 0 & 0 & 0 & 0 & 0 & 0 \\
\hline 10 & $|Y M|$ & 0 & 0 & 0 & 0 & 0 & 0 \\
\hline 11 & $|\mathrm{RM}|$ & 0 & 0 & 0 & 0 & 0 & 0 \\
\hline 12 & $|\mathrm{AF}|$ & 0 & 0 & 0 & 0 & 0 & 0 \\
\hline 13 & IdTil & 0 & 0 & 0 & 0 & 0 & 0 \\
\hline 14 & $\mathrm{NF} * \mathrm{NF}$ & 0 & $-4.826970 e-09$ & $+1.636763 e-09$ & $+4.321590 e-10$ & $-1.195511 e-09$ & 0 \\
\hline 15 & $\mathrm{PM} * \mathrm{PM}$ & 0 & $-1.002329 e-11$ & $-2.856620 e-12$ & 0 & $+9.197795 e-12$ & 0 \\
\hline 16 & $Y M * Y M$ & 0 & $-4.679570 e-11$ & 0 & 0 & 0 & 0 \\
\hline 17 & $\mathrm{RM} * \mathrm{RM}$ & $+9.972107 e-13$ & 0 & $-4.587186 e-13$ & $+2.488519 e-13$ & 0 & 0 \\
\hline 18 & $\mathrm{AF} * \mathrm{AF}$ & 0 & $+8.041729 e-08$ & 0 & 0 & 0 & 0 \\
\hline 19 & $d T i * d T i$ & $+9.994229 e-03$ & $+8.791125 e-03$ & $+1.204632 e-02$ & $+9.032056 e-03$ & $+8.940470 e-03$ & 0 \\
\hline 20 & $N F *|N F|$ & 0 & 0 & 0 & 0 & 0 & 0 \\
\hline 21 & $\mathrm{PM} *|\mathrm{PM}|$ & 0 & 0 & 0 & 0 & 0 & 0 \\
\hline 22 & $Y M *|Y M|$ & 0 & 0 & 0 & 0 & 0 & 0 \\
\hline 23 & $\mathrm{RM} *|\mathrm{RM}|$ & 0 & 0 & 0 & 0 & 0 & 0 \\
\hline 24 & $A F *|A F|$ & 0 & 0 & 0 & 0 & 0 & 0 \\
\hline 25 & dTi*ldTil & 0 & 0 & 0 & 0 & 0 & 0 \\
\hline 26 & $N F * P M$ & 0 & 0 & 0 & 0 & 0 & 0 \\
\hline 27 & $N F * Y M$ & 0 & 0 & 0 & 0 & 0 & 0 \\
\hline 28 & $N F * R M$ & 0 & 0 & 0 & 0 & 0 & 0 \\
\hline 29 & $\mathrm{NF} * \mathrm{AF}$ & 0 & 0 & 0 & 0 & 0 & 0 \\
\hline 30 & $\mathrm{NF} * \mathrm{dTi}$ & 0 & 0 & 0 & 0 & 0 & 0 \\
\hline 31 & $P M * Y M$ & $+2.035398 \mathrm{e}-11$ & 0 & 0 & $+5.196233 e-12$ & 0 & 0 \\
\hline 32 & $\mathrm{PM} * \mathrm{RM}$ & 0 & $+1.670685 e-12$ & $+4.786468 \mathrm{e}-12$ & $+1.122090 e-12$ & $+5.630559 e-10$ & 0 \\
\hline 33 & $\mathrm{PM} * \mathrm{AF}$ & 0 & 0 & 0 & 0 & 0 & 0 \\
\hline 34 & $\mathrm{PM} * \mathrm{dTi}$ & 0 & 0 & 0 & 0 & 0 & 0 \\
\hline 35 & $Y M * R M$ & 0 & 0 & 0 & 0 & 0 & 0 \\
\hline 36 & $\mathrm{YM} * \mathrm{AF}$ & 0 & 0 & 0 & 0 & 0 & 0 \\
\hline 37 & $\mathrm{YM} * \mathrm{dTi}$ & 0 & 0 & 0 & 0 & 0 & 0 \\
\hline 38 & $\mathrm{RM} * \mathrm{AF}$ & $+9.028544 e-10$ & $+8.563216 e-10$ & $-1.694094 e-10$ & $-5.355663 e-11$ & $+1.789840 e-10$ & 0 \\
\hline 39 & $\mathrm{RM} * \mathrm{dTi}$ & 0 & 0 & 0 & 0 & 0 & 0 \\
\hline 40 & $A F * d T i$ & 0 & 0 & 0 & 0 & 0 & 0 \\
\hline
\end{tabular}

Fig. 4 Computed regression coefficients of the gage outputs of the ARC-30K balance. 


\begin{tabular}{|c|c|c|c|c|c|c|c|}
\hline INDEX & TERM & $\mathrm{NF}$ & PM & YM & RM & AF & $\mathrm{dTi}$ \\
\hline 1 & INTERCEPT & $-9.012208 e+01$ & $-1.123363 e+02$ & $-6.386578 e+01$ & $-4.050774 \mathrm{e}+01$ & $+3.452281 e+01$ & 0 \\
\hline---- & ------ & -ーー-ー-ー-ー- & \multicolumn{5}{|c|}{ MATRIX DO [TRANSPOSE $(\mathrm{C} 1 \mathrm{INV})]-------------$} \\
\hline- & $\mathrm{rNF}$ & $+2.472099 \mathrm{e}+01$ & $-3.606828 \mathrm{e}-01$ & $-7.289978 \mathrm{e}-01$ & $+4.490572 \mathrm{e}+01$ & $+2.317580 e-02$ & 0 \\
\hline- & rPM & $+4.745023 e-01$ & $+1.801374 \mathrm{e}+02$ & $-2.443032 e-01$ & $-3.181481 e-01$ & $+1.160800 e-02$ & 0 \\
\hline- & rYM & $+4.265486 \mathrm{e}-02$ & $-1.687709 e-01$ & $+3.257867 \mathrm{e}+02$ & $+5.456691 \mathrm{e}-01$ & $+1.005371 \mathrm{e}-02$ & 0 \\
\hline- & rRM & $-5.517033 e-01$ & $+7.560966 \mathrm{e}-01$ & $-1.112764 \mathrm{e}+00$ & $+9.434077 \mathrm{e}+02$ & $+5.849231 \mathrm{e}-03$ & 0 \\
\hline - & rAF & $+1.162634 \mathrm{e}-01$ & $-1.584171 e-01$ & $+6.661061 e-01$ & $-2.615806 e-01$ & $+2.523147 \mathrm{e}+00$ & 0 \\
\hline- & dT & $-2.492135 e+01$ & $-1.981325 e+02$ & $-2.917864 e+02$ & $-7.995899 e+02$ & $-1.815875 e+00$ & $+1.000000 e+00$ \\
\hline---- & ------ & --------- & \multicolumn{5}{|c|}{ MATRIX D1 [MATRIX IS NOT USED] ------------------- } \\
\hline 2 & $\mathrm{NF}$ & 0 & 0 & 0 & 0 & 0 & 0 \\
\hline 3 & PM & 0 & 0 & 0 & 0 & 0 & 0 \\
\hline 4 & YM & 0 & 0 & 0 & 0 & 0 & 0 \\
\hline 5 & RM & 0 & 0 & 0 & 0 & 0 & 0 \\
\hline 6 & $\mathrm{AF}$ & 0 & 0 & 0 & 0 & 0 & 0 \\
\hline 7 & $\mathrm{dTi}$ & 0 & 0 & 0 & 0 & 0 & 0 \\
\hline-- & --- & --------- & \multicolumn{5}{|c|}{ MATRIX D2 [TRANSPOSE(C1INVC2)] -------------------------} \\
\hline 8 & INFI & 0 & 0 & 0 & 0 & 0 & 0 \\
\hline 9 & IPMI & 0 & 0 & 0 & 0 & 0 & 0 \\
\hline 10 & IYMI & 0 & 0 & 0 & 0 & 0 & 0 \\
\hline 11 & IRMI & 0 & 0 & 0 & 0 & 0 & 0 \\
\hline 12 & $|A F|$ & 0 & 0 & 0 & 0 & 0 & 0 \\
\hline 13 & $|d T i|$ & 0 & 0 & 0 & 0 & 0 & 0 \\
\hline 14 & $N F * N F$ & $-2.598010 e-09$ & $-8.692779 e-07$ & $+5.331378 \mathrm{e}-07$ & $+4.104436 \mathrm{e}-07$ & $-3.053497 e-09$ & 0 \\
\hline 15 & $\mathrm{PM} * \mathrm{PM}$ & $-3.808554 e-12$ & $-1.806544 e-09$ & $-9.220733 e-10$ & $-7.758450 e-13$ & $+2.306232 e-11$ & 0 \\
\hline 16 & $Y M * Y M$ & $-2.220467 e-11$ & $-8.429656 e-09$ & $+1.143234 \mathrm{e}-11$ & $+1.488796 \mathrm{e}-11$ & $-5.432044 e-13$ & 0 \\
\hline 17 & $\mathrm{RM} * \mathrm{RM}$ & $+2.449517 \mathrm{e}-11$ & $-9.410233 e-14$ & $-1.504483 e-10$ & $+2.792989 \mathrm{e}-10$ & $+1.995492 e-14$ & 0 \\
\hline 18 & $A F * A F$ & $+3.815819 \mathrm{e}-08$ & $+1.448616 e-05$ & $-1.964620 e-08$ & $-2.558460 e-08$ & $+9.334837 e-10$ & 0 \\
\hline 19 & $\mathrm{dTi} * \mathrm{dTi}$ & $+2.478089 \mathrm{e}-01$ & $+1.583385 e+00$ & $+3.911004 \mathrm{e}+00$ & $+8.971147 \mathrm{e}+00$ & $+2.306573 e-02$ & 0 \\
\hline 20 & $N F *|N F|$ & 0 & 0 & 0 & 0 & 0 & 0 \\
\hline 21 & $P M * \mid P M I$ & 0 & 0 & 0 & 0 & 0 & 0 \\
\hline 22 & $Y M *|Y M|$ & 0 & 0 & 0 & 0 & 0 & 0 \\
\hline 23 & $\mathrm{RM} * \mid \mathrm{RMI}$ & 0 & 0 & 0 & 0 & 0 & 0 \\
\hline 24 & $A F *|A F|$ & 0 & 0 & 0 & 0 & 0 & 0 \\
\hline 25 & $\mathrm{dTi} * \mathrm{dT} i \mathrm{l}$ & 0 & 0 & 0 & 0 & 0 & 0 \\
\hline 26 & $\mathrm{NF} * \mathrm{PM}$ & 0 & 0 & 0 & 0 & 0 & 0 \\
\hline 27 & $N F * Y M$ & 0 & 0 & 0 & 0 & 0 & 0 \\
\hline 28 & $\mathrm{NF} * \mathrm{RM}$ & 0 & 0 & 0 & 0 & 0 & 0 \\
\hline 29 & $\mathrm{NF} * \mathrm{AF}$ & 0 & 0 & 0 & 0 & 0 & 0 \\
\hline 30 & $\mathrm{NF} * \mathrm{dTi}$ & 0 & 0 & 0 & 0 & 0 & 0 \\
\hline 31 & $P M * Y M$ & $+5.003037 \mathrm{e}-10$ & $-3.412476 e-12$ & $-2.062019 \mathrm{e}-11$ & $+5.816177 \mathrm{e}-09$ & $+5.021137 e-13$ & 0 \\
\hline 32 & $P M * R M$ & $+6.584066 e-11$ & $+2.117957 e-10$ & $+1.932766 \mathrm{e}-09$ & $+9.133842 \mathrm{e}-10$ & $+1.420747 \mathrm{e}-09$ & 0 \\
\hline 33 & $\mathrm{PM} * \mathrm{AF}$ & 0 & 0 & 0 & 0 & 0 & 0 \\
\hline 34 & $\mathrm{PM} * \mathrm{dTi}$ & 0 & 0 & 0 & 0 & 0 & 0 \\
\hline 35 & $Y M * R M$ & 0 & 0 & 0 & 0 & 0 & 0 \\
\hline 36 & $Y M * A F$ & 0 & 0 & 0 & 0 & 0 & 0 \\
\hline 37 & $Y M * d T i$ & 0 & 0 & 0 & 0 & 0 & 0 \\
\hline 38 & $R M * A F$ & $+2.276891 \mathrm{e}-08$ & $+1.538896 e-07$ & $-5.587988 \mathrm{e}-08$ & $-1.039411 e-08$ & $+4.804510 e-10$ & 0 \\
\hline 39 & $\mathrm{RM} * \mathrm{dTi}$ & 0 & 0 & 0 & 0 & 0 & 0 \\
\hline 40 & $\mathrm{AF} * \mathrm{dTi}$ & 0 & 0 & 0 & 0 & 0 & 0 \\
\hline
\end{tabular}

Fig. 5 Data reduction matrix for the iterative prediction of loads that act on the ARC-30K balance. 
$\triangle N F, \%$ OF CAPACITY ; STANDARD DEVIATION $=15.5039$ [lbs] OR $0.0517 \%$

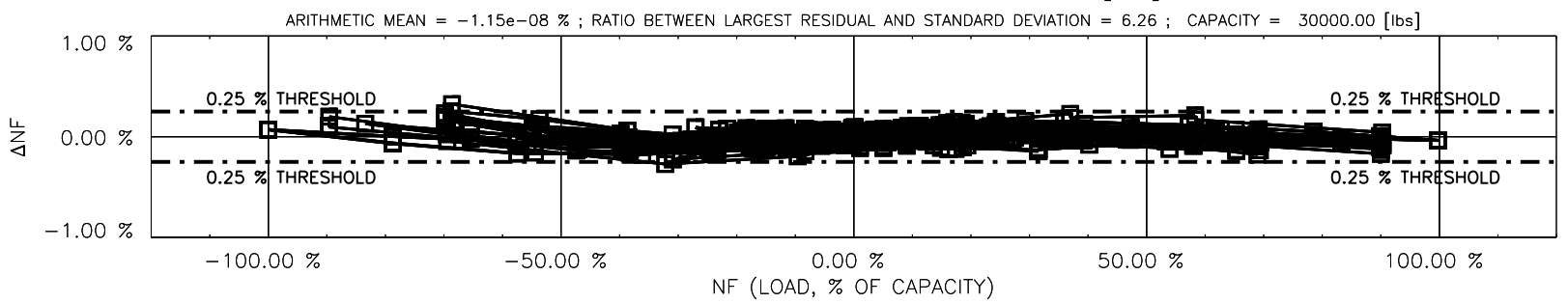

$\triangle P M, \%$ OF CAPACITY ; STANDARD DEVIATION = 166.8688 [in-lbs] OR $0.0556 \%$

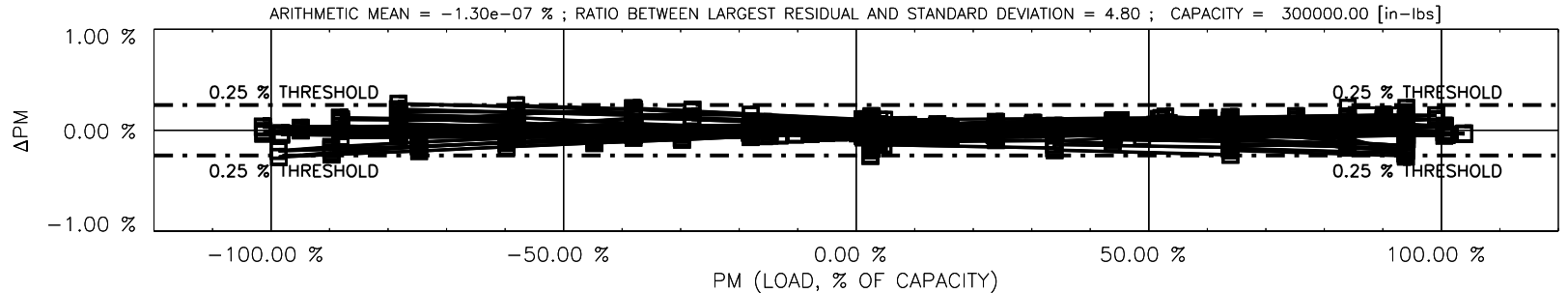

$\triangle Y M, \%$ OF CAPACITY; STANDARD DEVIATION $=262.3232$ [in-lbs] OR $0.1749 \%$

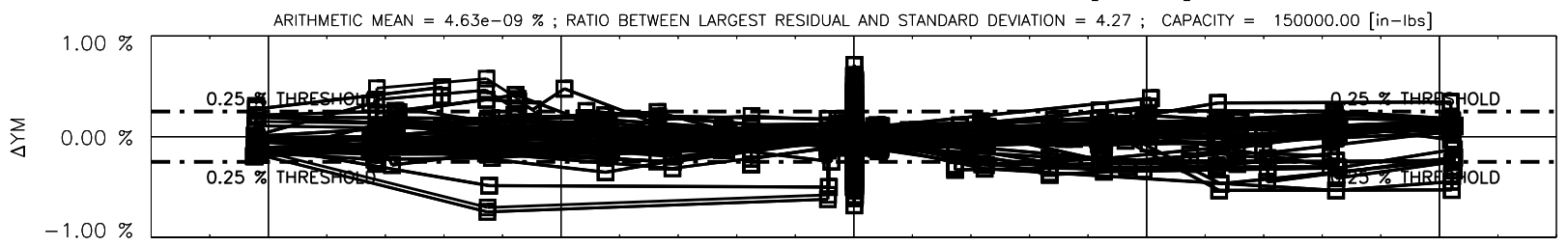

$\begin{array}{ccc}-100.00 \% & -50.00 \% & 0.00 \% \\ & \text { YM (LOAD, \% OF CAPACITY) }\end{array}$

$\triangle R M, \%$ OF CAPACITY; STANDARD DEVIATION $=194.6066$ [in-lbs] OR $0.0150 \%$

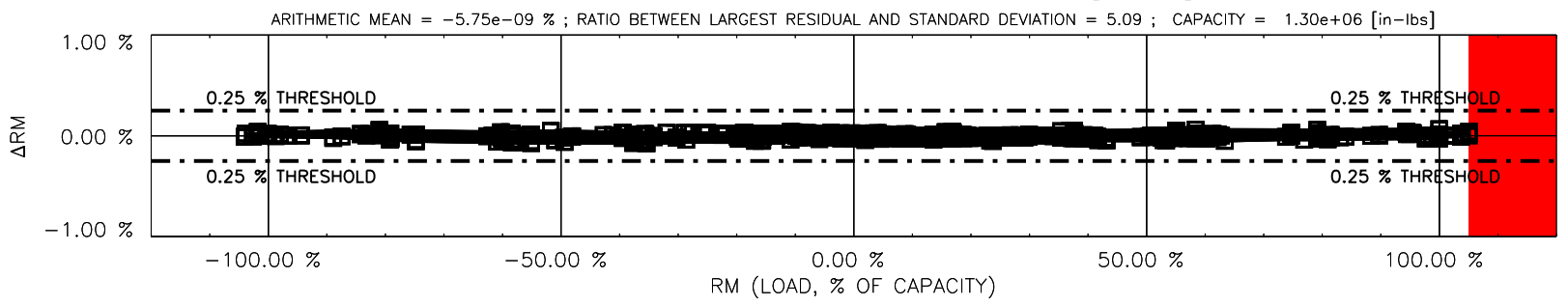

$\triangle A F, \%$ OF CAPACITY; STANDARD DEVIATION $=4.0130$ [Ibs] OR $0.1338 \%$

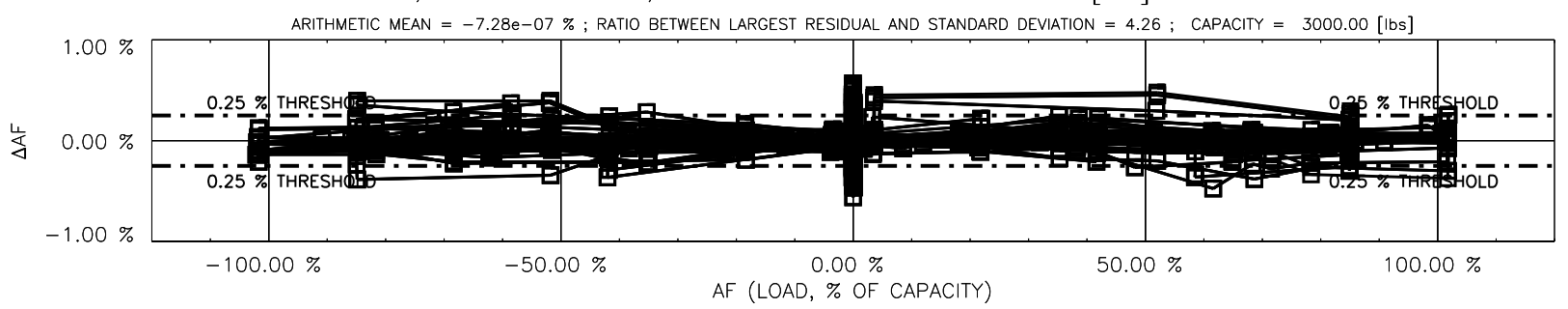

Fig. 6 Load residuals for the simulated temperature-dependent balance calibration data. 